\title{
Contexto de trabalho das pessoas com deficiência no serviço público federal: contribuições do inventário sobre trabalho e riscos de adoecimento
}

\author{
Work context of people with disabilities in the federal public service: \\ contributions of the inventory of work and illness risks
}

\author{
Celina Hoffmann ${ }^{1}$ \\ Luciana Davi Traverso \\ Roselaine Ruviaro Zanini'
}

\begin{abstract}
Resumo: Este trabalho teve como objetivo identificar os antecedentes, medidores e efeitos do trabalho no processo de adoecimento dos servidores com deficiência que trabalham no serviço público federal de Santa Maria, por meio da aplicação do Itra. Este instrumento é composto por 4 escalas (EACT; ECHT; EIPST; EADRT) e tem como objetivo traçar um perfil dos antecedentes, medidores e efeitos do trabalho no processo de adoecimento, além de avaliar algumas dimensões da inter-relação trabalho e processo de subjetivação. Foram entrevistadas 14 pessoas com deficiência, estando distribuídas num total de 6 instituições públicas pertencentes à administração indireta. Os principais resultados apontam que os fatores indicadores de sofrimento não representam, na população pesquisada, existência de danos relacionados ao trabalho, sendo que os aspectos que denotaram vivências positivas como a "liberdade de expressão" e "realização profissional" apresentaram maior representatividade entre os fatores componentes das escalas.
\end{abstract}

Palavras-chave: Gestão de recursos humanos. Administração pública. Condições de trabalho. Pessoas com deficiência. Psicodinâmica do trabalho.

\begin{abstract}
This study aimed to identify the antecedents, effects and gauges of work in the illness process of civil servants with disabilities, who work in the federal public service in the municipality of Santa Maria, Rio Grande do Sul state, Brazil, through the application of the Inventory of Work and Illness Risks (ITRA). This instrument consists of 4 scales (EACT; ECHT; EIPST; EADRT;) and aims to draw a profile of the antecedents, effects and gauges of work in illness processes to evaluate some aspects of the relationship between work and process of subjectivation. We interviewed 14 people with disabilities distributed in a total of 6 public institutions belonging to the indirect administration. The main results show that factors which indicate suffering are not representative of damage related to work in the population studied, and the aspects that denote positive experiences, such as "freedom of expression" and "professional achievement", showed higher representativeness among the component factors of the scales used.
\end{abstract} Keywords: People management. Government. Working conditions. People with disabilities. Psychodynamic of work.

\section{Introdução}

A relação entre as pessoas com deficiência e o acesso ao trabalho apresenta trajetória recente. As medidas de inclusão como ações afirmativas fazem parte da construção de uma sociedade mais justa e igualitária, capaz de dignificar, quem antes era excluído, por meio da inserção no ambiente de trabalho. O histórico é marcado pela década de oitenta; quando o ano de 1981 foi declarado o ano internacional da pessoa deficiente pela Organização Mundial das Nações Unidas. A partir disso, deu-se início à transgressão do paradigma de exclusão para modificação de padrões culturais alicerçados no preconceito e assistencialismo.

O Brasil refletiu tal movimento a partir da promulgação da Constituição de 1988, que considerou alguns temas relevantes, como acessibilidade, trabalho, e educação voltados às pessoas com deficiência. Além de conceber e regulamentar uma série de dispositivos legais no intuito de garantir direitos essenciais, como a Lei n. 8.112 de 1990 (BRASIL, 1991a) que estabeleceu a reserva de vagas em concursos públicos, a Lei n. 8.213 de 1991 (BRASIL, 1991b), chamada

\footnotetext{
${ }^{1}$ Programa de Pós-graduação em Engenharia de Produção, Centro de Tecnologia, Universidade Federal de Santa Maria - UFSM, CEP 97105-900, Santa Maria, RS, Brasil, e-mail: celina_hoffmann@hotmail.com; rrzanini@terra.com.br

${ }^{2}$ Unidade Descentralizada de Educação Superior - UDESSM, Universidade Federal de Santa Maria - UFSM, CEP 97195-000, Silveira Martins, RS, Brasil, e-mail: luciana.traverso@ufsm.br
} 
"Lei de cotas", que estabeleceu valores percentuais de contratações para empresas da iniciativa privada, e o Decreto n. 5.296 de 2004 (BRASIL, 2004), que define critérios de avaliação sobre cada tipo de deficiência para adequação legal quanto ao recebimento de benefício pago pela União.

Diante da complexidade da temática que envolve a inserção das pessoas com deficiência no mercado de trabalho, percebeu-se o aumento da produção científica voltada à investigação e proposição de melhoria quanto aos processos de pós-inserção no trabalho. Visto que ainda é uma realidade pouco conhecida e, muitas vezes, retratada com primarismo, já que as empresas públicas e privadas tiveram que se adequar à nova realidade imposta pela legislação vigente.

O consenso parte da premissa que trata da "plena inclusão ao trabalho" e os aspectos que a envolvem, que vão além do simples cumprimento da legislação vigente, neste aparato inclui-se a subjetividade das relações entre colegas e chefias, que, muitas vezes, reflete o histórico de discriminação e segregação, como ações marcadas pela subestimação de habilidades e capacidades, tratamento paternalista e assistencialista, e demais constrangimentos. Neste contexto, Vasconcelos (2010, p. 41) identificou, entre as estratégias de inclusão, o que chamou de "ironias da desigualdade", entre as quais, citou:

[...] a ameaça de chefes a empregados, obrigando-os a tratar os 'deficientes' como 'normais', a visão da deficiência como virtude, por facilitar o acesso ao emprego, e a utilização do deficiente como exemplo de 'bom trabalhador' [...].

Entram em questionamento as vivências de prazer e sofrimento no trabalho e suas influencias trazidas às pessoas com deficiência. Sob este prisma atua a Psicodinâmica do Trabalho, a chamada de teoria crítica do trabalho, que contempla modelos conceituais que tratam da dinâmica dos processos subjetivos nas relações de trabalho, vivências de prazer e sofrimento que podem ou não levar ao adoecimento (MENDES, 2007a).

Complementarmente, a literatura nacional é incipiente em estudos que investiguem os processos de pós-inserção das pessoas com deficiência no âmbito do setor público federal, que deveria representar as boas práticas de gestão da diversidade e inclusão. Diante disso, o presente estudo tem como objetivo identificar os antecedentes, medidores e efeitos do trabalho no processo de adoecimento dos servidores com deficiência que trabalham no serviço público federal de Santa Maria, como forma de inspirar novas pesquisas sobre o tema, além de fornecer resultados a serem considerados sobre a realidade investigada.

\section{Referencial teórico}

O referencial teórico procurou condizer com a transversalidade do tema, por isso, subdivide-se em: a) Inclusão das Pessoas com Deficiência no Trabalho; b) Psicodinâmica do Trabalho e estudos aplicados na área.

\subsection{A inclusão das pessoas com deficiência no trabalho}

Os dispositivos jurídicos que fazem parte das políticas de ações afirmativas têm como finalidade prevenir atos discriminatórios a grupos minoritários, no que se refere ao acesso ao trabalho das pessoas com deficiência, pressupõe-se que

[...] o trabalho associado a um emprego desempenha um papel importante entre os grupos historicamente marginalizados, contribuindo para diminuição das taxas de pobreza, do isolamento social e para o aumento a participação política destes grupos. (CARVALHO-FREITAS, 2009, p. 123).

A partir da discussão sobre pessoas com deficiência e mercado de trabalho promovida, em um primeiro momento, pelo ambiente jurídico-legal, verificou-se crescente interesse de pesquisadores de diversas áreas, como Gestão da Diversidade, Análise Ergonômica do Trabalho, Psicologia, e Terapia Ocupacional no sentido de perceber, tanto em termos quantitativos quanto qualitativos, de que forma tem ocorrido a inserção e gestão destas pessoas no ambiente de trabalho. A partir disso, tornaram-se evidentes lacunas e falhas existentes nos processos de pós-inserção com origens de causa diversas como a ineficiência da legislação vigente e o despreparo de dirigentes e equipe de trabalho em receber e gerir estes profissionais (CARVALHOFREITAS et al., 2010; VASCONCELOS, 2010; SIMONELLI; CAMAROTTO, 2011; GARCIA, 2014; PEREIRA; PASSERINO, 2012; BELTRÃO; BRUNSTEIN, 2012).

Segundo Simonelli e Camarotto (2011, p. 25), o excesso de apego às normas ligadas a aspectos técnicos desconsideram as particularidades tão essenciais ao processo de inclusão, “[...] não é possível generalizar as barreiras e as limitações de uma pessoa pela classificação de doenças [...]", a partir disso, os autores propuseram um modelo de inclusão que considera as habilidades/restrições e análise da atividade. Nesta perspectiva, inclui-se o desafio imposto às empresas e gestores no sentido de avaliar as especificidades de cada posto de trabalho em concomitância com as necessidades da pessoa com deficiência recém-contratada. Neste âmbito, decorre necessidade de complemento à Lei no sentido de conceber diretrizes que facilitem as ações de inclusão de acordo com cada tipo de deficiência e respectiva atividade laboral. 
No que condiz com a análise econômica do trabalho, Garcia (2014) aponta uma defasagem em termos quantitativos quanto ao contingente de pessoas com deficiência inseridas no trabalho. Entre a população com idade produtiva que apresenta algum tipo de deficiência, há apenas 4,9\% inseridos no mercado de trabalho formal, o que denota que a legislação imposta às empresas não tem sido suficiente para que ocorra inclusão efetiva. A partir disso, deve-se considerar a investigação sobre a fiscalização dada às empresas, além da necessidade em identificar possíveis causas capazes de explicar o baixo número de contratação.

No caso do setor privado, de acordo com Brasil (2011, p. 21)

Cabe ressaltar que a falta de capacitação profissional adequada é o principal argumento evocado por empregadores para a não integralização das cotas para pessoas com deficiência.

Diante disso foi criado projeto de qualificação que visa ajudar as empresas no preenchimento das cotas destinadas às pessoas com deficiência, que consiste na efetivação como aprendizes por até dois anos, mediante oferta de cursos de qualificação em conformidade com atividade laboral, para posterior colocação profissional dentro da empresa.

No setor público, a situação torna-se ainda mais preocupante, conforme menciona Bonfante (2007, p. 11), apesar da reserva de vagas, faltam dispositivos legais para regulamentar a questão da nomeação. Nesse sentido, a autora alerta:

Não tendo sido a forma de contratação das pessoas com deficiência regulamentada, não há qualquer previsão legal sobre os passos que deveriam ser seguidos após o encerramento do concurso, ou seja, na etapa de admissão dos candidatos.

Esta considerável lacuna abre possibilidades de restrição ao acesso da pessoa com deficiência ao cargo público, que passa a ser uma decisão individual do gestor público que encontra subsídio legal para amparar sua decisão, tendo sido identificados casos em que a nomeação não ocorre.

Tão importante quanto a reserva de vagas e efetiva contratação das pessoas com deficiência, faz-se pertinente o assunto que trata do desenvolvimento profissional destes após a inserção no contexto do trabalho. Sob este prisma as autoras Beltrão e Brunstein (2012), em estudo de caso, perceberam que as iniciativas organizacionais para construção e desenvolvimento de competências voltadas às pessoas com deficiência encontraram-se restritas às características biológicas. Dessa forma, deixam de avançar na carreira pelas empresas desconsiderarem seu potencial.
Sob o enfoque dado ao processo de socialização organizacional, Carvalho-Freitas et al. (2010) evidenciaram comportamento proativo por parte das pessoas com deficiência e apontaram necessidades de adaptação por parte da organização quanto à formalização e institucionalização de estratégias de socialização. Neste contexto, pode-se sugerir que a mobilização em maior grau por parte das pessoas com deficiência pode demonstrar receio e medo de perda do emprego.

Pereira e Passerino (2012, p. 262) reforçam tal resultado ao afirmar:

É preciso educar a empresa para a inclusão, enquanto não se estabelecer esta meta as organizações ainda verão a lei de cotas como um problema intransponível ou uma arbitrariedade das políticas públicas.

Vasconcelos (2010) reforça esta ideia ao considerar que a implementação do sistema de cotas não é por si só suficiente, as estratégias de inclusão devem contemplar, o desenvolvimento e reabilitação para o trabalho, considerando todos os membros envolvidos.

Embora seja visível o esforço das políticas públicas em favor da inserção das pessoas com deficiência no ambiente de trabalho público e privado, parece haver um consenso sobre a necessidade de adequação do papel das empresas e respectivos gestores após o mero cumprimento da lei, o desafio da inclusão é ainda maior quando colocada em pauta a subjetividade do trabalho, as relações interpessoais e seus reflexos nas vivências de prazer e sofrimento no trabalho.

\subsection{Psicodinâmica do Trabalho}

A psicodinâmica do trabalho é uma abordagem científica voltada para o entendimento das interações dinâmicas no ambiente de trabalho. Esta abordagem foi desenvolvida por Cristophe Dejours, nos anos noventa, na França, tendo sido, inicialmente, construída com referenciais teóricos da psicopatologia, evoluindo para uma construção própria, devido aos progressos adquiridos por meio de pesquisas (MENDES, 2007a).

A abordagem baseia-se nas análises feitas a partir de interações ocorridas em determinados contextos do trabalho, em que, de acordo com Mendes (2007a, p. 29), estão presentes a

[...] atuação de forças, visíveis e invisíveis, objetivas e subjetivas, psíquicas, sociais, políticas e econômicas que podem ou não deteriorar esse contexto, transformando-o em lugar de saúde e/ ou de patologias e de adoecimento.

Do ponto de vista epistemológico, a psicodinâmica do trabalho é considerada uma "teoria crítica do trabalho" sendo que, a partir daí, tem-se as contribuições desta abordagem para o entendimento 
da saúde do trabalho, principalmente, no que condiz com a relação entre a organização do trabalho e os processos de subjetivação dos empregados.

Entende-se por processo de subjetivação no trabalho o meio pelo qual o trabalhador atribui sentido em relação à sua realidade de trabalho, expresso pelos modos de pensar, sentir e agir de maneira individual ou coletiva. Desta maneira, é fundamental para os estudos relacionados à psicodinâmica do trabalho a consideração das exigências de mobilização e engajamento que partem das empresas para o empregado. Estes aspectos determinam as formas de subjetivação que ocorrerão no contexto do trabalho, podendo até mesmo gerar ferramentas capazes de atender aos requisitos impostos pela ideologia produtivista, do desempenho e da excelência, que estão cada vez mais presentes nas organizações (MENDES, 2007b).

Na visão da psicodinâmica do trabalho, o sofrimento surge do descompasso gerado na relação entre o trabalhador e as demandas da organização. A partir disso, o contexto de trabalho pode ser reconhecido como fonte de construção da identidade e prazer como também pode ser reconhecido como fonte de alienação e sofrimento. Neste sentido, o sofrimento pode representar um mecanismo para obtenção da produtividade, entretanto este mesmo sofrimento pode, muitas vezes, provocar o comprometimento da saúde do trabalhador (MENDES, 2007b). Dessa forma, a psicodinâmica do trabalho introduz o "saudável" como resultante de um compromisso entre o sofrimento e estratégias de defesa individuais.

A saída para a transformação do sofrimento em prazer está na própria organização do trabalho, pois, para a psicodinâmica do trabalho, é possível vivenciar prazer mesmo em contextos precarizados, desde que a organização do trabalho ofereça condições para o trabalhador desenvolver três importantes ações: mobilização da inteligência prática, do espaço público da fala e da cooperação. Nesse sentido, a Psicodinâmica do Trabalho configura-se em uma perspectiva de pesquisa e ação sobre o trabalho, como uma análise crítica e proposta para a reconstrução deste ambiente.

\subsection{Estudos aplicados em Psicodinâmica do Trabalho}

Diante da subjetividade inerente à análise das vivências de prazer e sofrimento no trabalho e das restrições de análise ocasionadas pelas especificidades de diferentes categorias profissionais, buscou-se relacionar estudos recentes subsidiados pela teoria da Psicodinâmica do Trabalho, com a finalidade de subsidiar as análises do presente estudo. Entre outros aspectos, observou-se nas pesquisas considerável tendência por estudos de caso de caráter qualitativo no intuito de analisar, isoladamente cada categoria profissional.

Em relação aos bancários, categoria profissional que caracteriza o mundo do trabalho contemporâneo quanto à intensificação da indissociação entre trabalho e vida particular, Santos Júnior, Mendes e Araujo (2009, p. 624), em estudo com profissionais afastados por doenças de ordem musculoesqueléticas (ler/dort), evidenciaram vivências de sofrimento oriundas da organização do trabalho:

[...] os mecanismos organizacionais dessa categoria parecem estimular a superexploração do corpo, a autoaceleração e a negação de si mesmo e do outro [...],

além disso, os autores descartaram a influência da personalidade para o aparecimento destas doenças, sendo preponderante o papel da organização do trabalho.

Anchieta et al. (2011, p. 199) realizaram estudo com policiais civis de início de carreira localizados no Distrito Federal, mediante aplicação do inventário sobre trabalho e riscos de adoecimento (Itra), mesmo instrumento utilizado na presente pesquisa. Os resultados não identificaram danos à saúde do públicoalvo do estudo:

[...] apesar de não ficarem evidentes danos graves à saúde do policial novato, há riscos de acontecerem falhas nas estratégias de mediação em relação a fatores que levam ao adoecimento.

De acordo com as autoras, os fatores advindos da organização do trabalho foram classificados como críticos, e por isso requerem atenção quanto à manutenção de estratégias defensivas capazes de amenizar os efeitos negativos do trabalho sobre a saúde.

Em estudo com operadores de uma empresa de Call Center, os autores Scolari, Costa e Mazzilli (2009, p. 572) analisaram as vivências de prazer e sofrimento, de forma qualitativa. Os resultados demonstraram a existência de equilíbrio entre prazer e sofrimento, no qual apareceram as mediações no trabalho. De acordo com os autores: "A hipótese de que os trabalhadores estão encontrando um meio de administrar os problemas da organização do trabalho parece se concretizar.” Nesse sentido, há uma compensação entre os fatores que geram prazer como o reconhecimento e os que geram sentimentos negativos ligados à estrutura e organização do trabalho.

Com relação aos técnicos de enfermagem de um pronto-socorro no Paraná, Garcia et al. (2012, p. 158) identificaram os sentimentos de prazer na prática laboral. Os resultados apontam para a cooperação da equipe de trabalho e principalmente para o reconhecimento, que advém do próprio profissional, do paciente e da sociedade, segundo reafirmam: 
O técnico de enfermagem necessita deste reconhecimento, sentindo-se, assim, motivado a enfrentar o sofrimento no trabalho, pois o ambiente hospitalar é um local de visibilidade social.

Em estudo realizado com profissionais de medicina nuclear com iodo - 131, os autores Silveira, Guilam e Oliveira (2013, p. 3169) alicerçados sob o contraponto da análise entre o trabalho prescrito e o trabalho real, mediante a subjetividade do trabalho, verificaram resultados surpreendentes:

[...] os entrevistados modificaram as prescrições. Desenvolveram mecanismos de defesa individuais, como a negação do risco, e estratégias defensivas coletivas, levando-os a maior enfrentamento do perigo como defesa.

Vilela, Garcia e Anchieta (2013, p. 535) analisaram as percepções sobre prazer e sofrimento no trabalho dos docentes ligados à faculdade de educação de uma universidade pública, mediante aplicação de uma das escalas componentes do Itra, denominada escala de Indicadores de prazer-sofrimento no trabalho. Os resultados indicaram que as vivências de prazer são preponderantes em relação às de sofrimento, no entanto, segundo os autores, o adoecimento foi inibido pelo uso eficaz de estratégias defensivas: "[...] o uso de estratégias defensivas se torna necessário para lidar com o esgotamento emocional e o estresse."

Leão e Silva (2012, p. 167) desenvolveram estudo de cunho qualitativo com o objetivo de investigar as vivências subjetivas de deficientes auditivos e físicos membros de uma empresa de grande porte, a análise dos discursos ocorreu sob a perspectiva da Psicodinâmica do Trabalho. Os resultados foram alarmantes. Para os entrevistados, a deficiência é percebida como limitação para o crescimento profissional, além disso, o ambiente organizacional não acolhe suas singularidades e lhes oferece ambiente de convivência precária. Neste contexto, as vivências de sofrimento sobrepujam as de prazer:

O desgaste físico e/ou psíquico foi recorrente nos relatos desse grupo, vivenciado como desproteção, preconceito, medo, monotonia e constrangimentos $[\ldots]$.

Esta pesquisa apresenta estreita relação com os propósitos do presente estudo, e seus resultados contribuem para o reforço das premissas relacionadas ao longo do referencial teórico.

Apesar da diversidade entre as categorias profissionais utilizadas nos estudos aplicados em Psicodinâmica do Trabalho, ficam evidentes alguns resultados que são comuns às realidades investigadas, por exemplo: a importância dada às vivências de prazer relacionadas ao reconhecimento no trabalho; o sofrimento oriundo da dimensão ligada à organização do trabalho; e a larga utilização de estratégias defensivas pela maioria dos profissionais pesquisados, já que não houve indícios de adoecimento.

\section{Metodologia}

A presente pesquisa pode ser classificada como descritiva, pois este tipo de pesquisa

[...] tem como objetivo primordial a descrição das características de determinada população ou fenômeno ou, então, o estabelecimento de relações entre variáveis. (GIL, 1994, p. 46).

Quanto ao método de levantamento e análise dos dados, foram utilizados os pressupostos da pesquisa quantitativa que é baseada no paradigma positivista, no qual a racionalidade predomina de forma absoluta e os métodos utilizados são eminentemente quantitativos (GOMES; ARAÚJO, 2005).

A escolha pelo setor público federal está atrelada ao papel do Estado como agente direto de elaboração e implementação das ações de inclusão das pessoas com deficiência no contexto do trabalho. Para tanto, iniciou-se a coleta de dados pela triagem de órgãos públicos federais enquadrados nas formas da administração indireta. A lista dos órgãos públicos federais atuantes no município foi proporcionada pela prefeitura de Santa Maria, perfazendo o total de 12 órgãos públicos federais da administração indireta: Receita Federal; Polícia Federal; Ministério da Agricultura Pecuária e Abastecimento (Mapa); Instituto Nacional de Metrologia, Qualidade e Tecnologia (Inmetro); Polícia Rodoviária Federal; Instituto Nacional de Seguridade Social (INSS); Banco do Brasil; Caixa Econômica Federal; Universidade Federal de Santa Maria (UFSM); Departamento Nacional de Infraestrutura de Transportes; Correios; Instituto Brasileiro do Meio Ambiente e dos Recursos Naturais Renováveis. Dentre estas instituições, foram identificados 6 órgãos públicos federais que apresentam em seu quadro funcional uma ou mais pessoas com deficiência, como mostra a Tabela 1.

Desta lista, foram identificadas 22 pessoas na condição pertinente a este estudo correspondendo à população total, no entanto a presente pesquisa contou com a participação de 14 pessoas. A realização desta pesquisa contou com a aprovação do Comitê de Ética em Pesquisa da Universidade Federal de Santa Maria, órgão responsável pela avaliação e acompanhamento dos aspectos éticos de todas as pesquisas envolvendo seres humanos. Os questionários e termos de consentimento livre e esclarecido foram enviados aos participantes da pesquisa por $e$-mail. Em alguns casos, foram entregues e, posteriormente, recolhidos pessoalmente nos locais de trabalho dos participantes.

O questionário envolveu dados do perfil socioeconômico e carreira, além das escalas 
pertencentes ao Inventário sobre Trabalho e Riscos de Adoecimento (Itra), instrumento desenvolvido e validado pelos grupos: Estudos e Pesquisas em Ergonomia Aplicada ao Setor Público (ErgoPublic) e Estudos e Pesquisas em Saúde e Trabalho (Gepsat), ambos do Instituto de Psicologia da Universidade de Brasília (MENDES; FERREIRA, 2007).

Este instrumento tem como objetivo traçar um perfil dos antecedentes, medidores e efeitos do trabalho no processo de adoecimento e avalia algumas dimensões da inter-relação trabalho e processos de subjetivação, e os efeitos que pode exercer no modo do trabalhador vivenciá-lo. É composto pelas seguintes escalas: a) escala de avaliação do contexto do trabalho (EACT); b) escala de custo humano do trabalho (ECHT); c) escala de indicadores prazer-sofrimento no trabalho (EIPST); d) escala de avaliação dos danos relacionados ao trabalho (EADRT); (MENDES; FERREIRA, 2007). Cada escala é formada por fatores específicos, conforme enumerados na Figura 1.

A análise dos dados é feita com base no ponto médio e desvio padrão; os parâmetros de avaliação são indicados na Tabela 2, conforme diretrizes dos autores do instrumento de pesquisa. Por meio do

Tabela 1. População da pesquisa.

\begin{tabular}{lc}
\hline \multicolumn{1}{c}{ Órgão público federal } & Pessoas com deficiência \\
\hline Receita Federal & 2 \\
Caixa Econômica Federal & 2 \\
Correios & 1 \\
Instituto Nacional de & 2 \\
Seguridade Social & \\
Banco do Brasil & 1 \\
Universidade Federal de & 14 \\
Santa Maria & \\
Total & $\mathbf{2 2}$ \\
\hline
\end{tabular}

software Statistica 9.1, foram elaborados gráficos ilustrativos da média e desvio padrão de cada fator que compõe cada escala do Itra.

\section{Resultados}

Quanto à síntese dos dados sobre o perfil socioeconômico das pessoas com deficiência no serviço público federal de Santa Maria, a distribuição entre os gêneros apresenta-se equilibrada com a participação de homens e mulheres em $50 \%$ cada. No contexto nacional, este cenário é refletido, segundo IBGE (INSTITUTO ..., 2010): 26,5\% das pessoas com algum tipo de deficiência são mulheres e 21,2 são homens, evidenciando maior prevalência de mulheres.

Quanto à faixa etária, tem-se a predominância de 43\% dos participantes acima de 40 anos; seguidos de $36 \%$ que possuem entre 30 e 40 anos, e $7 \%$ com menos de 30 anos de idade, sendo que $14 \%$ não responderam. Os resultados evidenciam um perfil maduro das pessoas com deficiência inseridas no serviço público federal, de acordo com dados do Censo 2010,

[...] o maior contingente de população com pelo menos uma deficiência ocorre na população de 40 a 59 anos, correspondendo a um total de 17 435955 pessoas. (INSTITUTO..., 2010, p. 78).

Em relação ao nível de escolaridade, $50 \%$ dos participantes apresentam nível superior, seguidos de $21 \%$ que possuem pós-graduação, e $14 \%$ com nível médio de escolaridade, enquanto outros $14 \%$ não responderam. Pode-se perceber que o nível de escolaridade dos entrevistados é alta, uma vez que este aspecto lhes empresta subsídios que lhes favorece a inserção na esfera do serviço público federal, como também condiciona para progressão na carreira. No âmbito nacional, o nível superior de escolaridade representa aspecto de instrução que possui menos

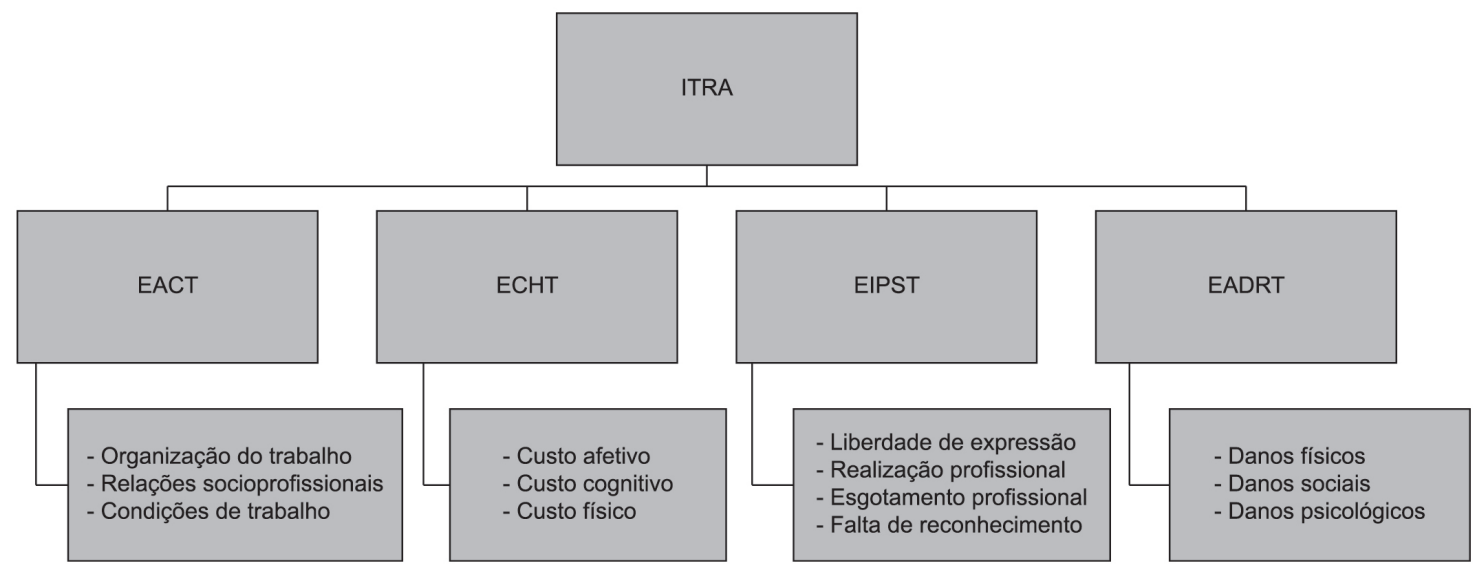

Figura 1. Descrição do Inventário sobre Trabalho e Riscos de Adoecimento (ITRA). Fonte: Elaborado com base em Mendes e Ferreira (2007). 
Tabela 2. Parâmetros de avaliação dos resultados.

\begin{tabular}{lcc}
\hline \multicolumn{1}{c}{ Escala } & Parâmetros & Nível \\
\hline Escala de Avaliação do Contexto & Acima de 3,7 & Grave \\
do Trabalho (EACT) & Entre 2,3 e 3,69 & Crítico \\
& Abaixo de 2,29 & Satisfatório \\
\hline Escala do Custo Humano no & Acima de 3,7 & Grave \\
Trabalho (ECHT) & Entre 2,3 e 3,69 & Crítico \\
& Abaixo de 2,29 & Satisfatório \\
\hline Escala de Indicadores de Prazer e & Acima de 4,0 & Satisfatório \\
Sofrimento no Trabalho (EIPST)* & Entre 3,9 e 2,1 & Crítico \\
& Abaixo de 2,0 & Grave \\
\hline Escala de Avaliação dos Danos & Acima de 4,1 & Grave \\
relacionados ao Trabalho & Entre 3,1 e 4,0 & Presença de doenças ocupacionais \\
(EADRT) & Entre 2,0 e 3,0 & Crítico \\
& Abaixo de 1,9 & Suportável \\
\hline
\end{tabular}

Fonte: Elaborado pelas autoras com base em Mendes e Ferreira (2007). *Para os fatores que compõem as vivências de sofrimento, os níveis de avaliação são inversos.

disparidade entre e pessoas com deficiência e pessoas sem deficiência, segundo dados do Censo 2010,

[...] a menor diferença estava no ensino superior completo: 6,7\% para a população de 15 anos ou mais com deficiência e $10,4 \%$ para a população sem deficiência (INSTITUTO..., 2010, p. 82).

Quanto à caracterização da deficiência, $86 \%$ possuem deficiência física, enquanto $14 \%$ possuem deficiência visual. Os demais tipos de deficiência não foram mencionados. Tal resultado é corroborado por outros estudos que também apontam a predominância de deficientes físicos inseridos no mercado de trabalho. Lancillotti (2003) explica que as barreiras arquitetônicas enfrentadas pelo deficiente físico, desde sua inclusão no ambiente educacional são consideradas mais amenas, se comparadas com as barreiras encontradas pelos demais tipos de deficiência. De acordo com depoimento recolhido por Vasconcelos (2010), o deficiente físico tem maior facilidade de integração à equipe de trabalho, uma vez que não possui restrições para o diálogo, como no caso dos deficientes auditivos.

\subsection{Dados profissionais}

Com relação ao contexto profissional dos sujeitos da pesquisa, têm-se como uma das características principais a predominância do regime estatutário (79\%) em detrimento do regime celetista (21\%). Quanto à opção pela reserva de vagas, subsidiada pela Lei 8.112/90 (BRASIL, 1991a), a maioria dos participantes (79\%) foi beneficiada, outros $14 \%$ responderam não ter optado, enquanto um deles (7\%) respondeu não ter optado porque na época que ingressou não havia esta opção no edital do concurso.
No que condiz ao tempo de serviço, a maior parte dos entrevistados $(46 \%)$ respondeu possuir mais de 10 anos de carreira, seguidos dos que possuem entre 5 e 10 anos (36\%), enquanto a menor parte $(21 \%)$ possui menos de 5 anos.

Quanto à oferta de cursos de qualificação por ano, $36 \%$ responderam participar de 1 a 2 cursos, e outros $36 \%$ participam de 3 ou mais. Se somados os percentuais perfazem o total de $72 \%$ do total que participam de algum curso, pelo menos uma vez ao ano. Em contrapartida, quando se refere à existência de cursos específicos às pessoas com deficiência, $71 \%$ alegou não ser disponibilizado este tipo de curso. Tal fator pode ser considerado prejudicial para a integração e desenvolvimento da pessoa com deficiência no trabalho, de acordo com Beltrão e Brustein (2012, p. 17)

A atenção às especificidades da deficiência deve ser observada pela empresa, pois o desenvolvimento de competências pode ser alavancado com o cuidado aos aspectos que representam uma limitação para a PcD inserida na organização.

Quanto à ocupação de cargos de chefia, entre os participantes, 3 homens e 1 mulher ocupam tais posições. No contexto do serviço público federal,

[...] a participação das mulheres em cargo de direção e assessoramento superior (DAS) é sempre menor que a dos homens. (MONTAGNER et al. 2010, p. 42);

no entanto, sobre este resultado deve-se ponderar a estrutura de carreira a qual cada participente está inserido, para que haja posterior investigação sobre 
o quantitativo de ocupações em cargos de chefia que possam refletir resultados sobre eventual segregação.

\subsection{Resultados do Itra}

Diante destes pressupostos, encontra-se o Itra, que consiste em um instrumento de pesquisa capaz de identificar percepções sobre o trabalho e indicadores de adoecimento. Sendo aplicado à realidade das pessoas com deficiência, este inventário adquire ainda mais importância, pois trata de um enfoque em que são raras as investigações. Os indicativos daí decorrentes expõem uma realidade peculiar a ser considerada, apresenta a visão destas pessoas sobre seu conteúdo de trabalho; para tanto, serão apresentados, na sequência, os resultados das quatro escalas que compõem o Itra.

Diante disso, apresentam-se, como início desta análise, os resultados dados pela escala EACT, que podem ser vistos na Figura 2, na qual estão relacionados os resultados para os três fatores que compõem esta escala: organização do trabalho; relações socioprofissionais; e condições do trabalho.

De acordo com Dejours e Abdoucheli (2011), a "organização do trabalho" é considerada elemento potencialmente desestabilizador para a saúde mental do trabalhador; segundo os autores, está relacionada à divisão do trabalho que envolve a definição do trabalho operacional prescrito, que estabelece ritmo e cadência do sistema produtivo propriamente dito; e à divisão humana, que envolve distribuição de responsabilidades, hierarquia, ordem e controle. Esta última mobiliza relações entre pessoas e estimula investimentos afetivos.

Tendo em vista os valores expostos, verifica-se que o fator "organização do trabalho" apresenta classificação de estado crítico, com média de 3,06. Ou seja, representa situação limite, na qual o custo negativo e sofrimento no trabalho se agravam: características como tarefas repetitivas, fiscalização quanto ao desempenho e divisão entre quem planeja e quem executa são típicas do ambiente do serviço público e justamente estes itens mais colaboraram para a avaliação de situação crítica. Ao encontrar resultado semelhante Leão e Silva (2012, p. 167) retrataram a organização do trabalho estudada como: "[...] marcadamente regulada por controles, ritmo, pressão e hierarquia que dificultam o acolhimento das singularidades desses trabalhadores."

Segundo Dejours e Abdoucheli (2011), as pressões do trabalho que têm como alvo o corpo condizem com as características relacionadas às condições de trabalho, sobre as quais médicos e ergonômicos dedicam seus estudos. Verifica-se por meio da Figura 2, que o resultado para o fator "condições de trabalho" apresenta nível satisfatório com média 1,9. Tal resultado denota que os esforços físicos advindos das

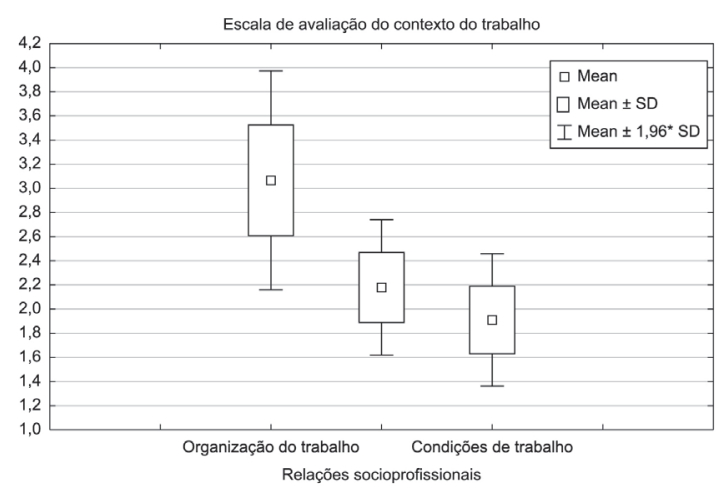

Figura 2. Resultados da EACT.

demandas do trabalho estão sendo percebidas como "adequadas" pelos participantes. Embora a legislação seja capaz de garantir a reserva de vagas em concursos públicos, faz-se necessária atenção à adaptabilidade da pessoa com deficiência a seu posto de trabalho, conforme ressaltam Simonelli e Camarotto (2011, p. 23) “[...] se não há método de estudo das tarefas de trabalho e da adaptação do trabalho às pessoas com deficiência, esta inserção é ineficaz."

Os conceitos que alicerçam a Psicodinâmica do Trabalho apoiam-se nos pressupostos da intersubjetividade e relações sociais de trabalho. Nesta perspectiva, incluem-se relações hierárquicas, de soliedariedade, subordinação, de reconhecimento, entre outras. Ou seja, fazem parte das "relações socioprofissionais" inerentes ao ambiente de trabalho. O resultado para este fator apresenta nível satisfatório, com média 2,18, o que denota aspecto positivo para as vivências de relações sociais nos contextos de trabalho. De acordo com resultados de estudo de CarvalhoFreitas et al. (2010), a percepção dos trabalhadores com deficiência sobre a receptividade da equipe de trabalho foi reconhecida, porém as iniciativas de socialização não eram institucionalizadas, por isso partiam dos próprios trabalhadores com deficiência.

Diante da avaliação do contexto de trabalho, em linhas gerais, é predominantemente satisfatória, apesar de o fator "organização do trabalho" ter apresentado avaliação crítica. Verifica-se que o maior desvio padrão condiz com este fator. Este resultado pode representar a diversidade do ambiente de trabalho de cada participante, além da disparidade entre as percepções, que são próprias de cada um. Enquanto os fatores "relações socioprofissionais" e "condições de trabalho" apresentaram pouca variabilidade entre as respostas, independente do contexto de trabalho, é fundamental a atenção e participação dos gestores públicos na verificação da adapatabilidade e inclusão dos servidores públicos com deficiência.

No que condiz com a avaliação da escala do custo humano do trabalho, os resultados para o "custo 
afetivo", "custo cognitivo" e "custo físico" podem ser verificados na Figura 3. Com relação ao "custo afetivo", apresenta nível crítico com média 2,39. De acordo com Mendes e Ferreira (2007), condiz com os aspectos ligados ao dispêndio emocional sob a forma de reações afetivas, sentimento e de estados de humor, que, de certa forma, estão relacionados à qualidade das relações interpessoais entre colegas, chefias e clientes e às demandas.

No que se refere ao custo cognitivo, apresenta média 3,54, sendo, portanto, o fator mais alterado desta escala representa o dispêndio intelectual para aprendizagem, resolução de problemas e tomada de decisão no trabalho. Os itens que colaboraram para tal resultado correspondem ao uso da memória, concentração mental e desafios intelectuais, que perfazem características típicas de atividades burocráticas, às quais os participantes estão sujeitos.

Neste contexto, os gestores públicos devem ficar atentos em monitorar o custo afetivo e cognitivo da função na qual estão inseridos os participantes da pesquisa, visto que cada um apresenta percepção distinta com relação aos mesmos aspectos do trabalho. Sob este prisma, Vasconcelos (2010, p. 41), ao citar Aristóteles (1979), lembra o princípio de “[...] tratar igualmente os iguais e desigualmente os desiguais, na medida em que eles se desigualam." Esta afirmativa nos faz refletir sobre a questão do ingresso facilitado ao cargo público dado às pessoas com deficiência, que ocorre por meio de concurso público com condições de disputa menos acirrada do que os demais candidatos. No entanto, a partir da prática laboral, os servidores com deficiência são submetidos às mesmas demandas e exigências inerentes ao cargo ao qual disputaram em termos desiguais em relação aos demais servidores públicos.

Quanto ao custo físico, apresenta nível satisfatório, com média 2,26, no entanto verifica-se que possui maior variabilidade entre as respostas, com maior desvio padrão com relação aos demais fatores. Entende-se que as diferentes percepções dadas pelos respondentes advêm de contextos de trabalho distintos, além disso, deve-se ponderar o ambiente físico ao qual o trabalhador é exposto, o tipo de deficiência e suas respectivas particularidades com relação ao grau de exigência física por ela imposta. Tal consideração reafirma a necessidade de estudo tarefa/tipo de deficiência já mencionado por Simonelli e Camarotto (2011) na revisão bibliográfica do presente estudo.

Quanto à avaliação referente à escala de indicadores de prazer-sofrimento no trabalho, no que condiz com os indicadores de vivências de prazer, que são "liberdade de expressão" e "realização profissional", apresenta, conforme a Figura 4, avaliação satisfatória com valores de médias 4,23 e 4,17, respectivamente.

Quanto aos itens que compõem o fator "liberdade de expressão", relacionados à liberdade para pensar,

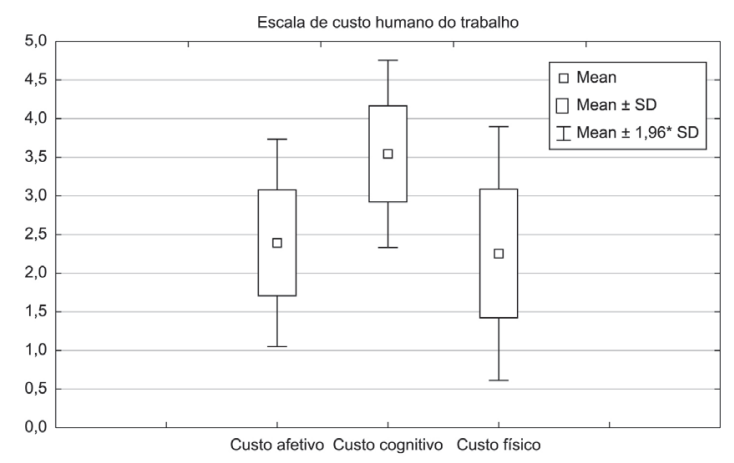

Figura 3. Resultados da EACHT.

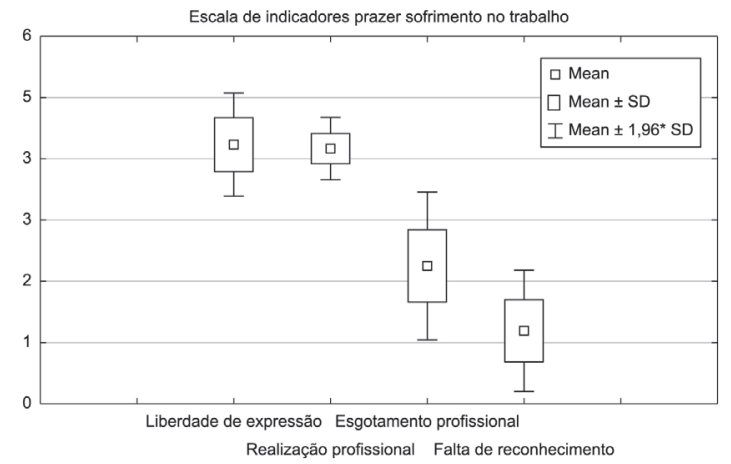

Figura 4. Resultados da EIPST.

organizar e falar sobre o seu trabalho (MENDES; FERREIRA, 2007), destacam-se a relevância dos aspectos ligados à cooperação, confiança e liberdade para falar com colegas que contribuíram em maior grau para a avaliação satisfatória deste fator. Tais características estão presentes em organizações que mantêm um adequado clima organizacional, em que os valores e a cultura são refletidos nas atitudes dos servidores. Além disso, também pode ser a estabilidade no serviço público que permite a vivência desta liberdade no contexto do trabalho, quando comparados os níveis de repreensão praticados pela maioria das organizações privadas.

O fator "realização profissional", que também apresentou avaliação satisfatória, exerce relação com as vivências de gratificação profissional, orgulho e identificação com o trabalho que faz (MENDES; FERREIRA, 2007). Destacam-se os itens referentes ao bem-estar, orgulho pelo que faz e a própria realização profissional; a partir desta perspectiva, tem-se evidência sobre a centralidade do trabalho para a vida das pessoas com deficiência. Vasconcelos (2010, p. 45) ao analisar a fala de uma participante de seu estudo, verifica a supervalorização da deficiência na medida em que representa subsídio para a inserção ao trabalho: "A deficiência é a condição que lhe deu acesso ao emprego e, portanto, é vista como positiva para a sua vida." 
Em relação aos fatores de vivências de sofrimento no trabalho, "esgotamento profissional" e a "falta de reconhecimento", os valores das médias apresentaram nível crítico $(2,26)$ e satisfatório $(1,2)$, respectivamente. Os itens "estresse" e "sobrecarga" foram os que mais influenciaram a avaliação crítica do fator "esgotamento no trabalho". Diante deste resultado, os participantes sinalizaram vivências de sofrimento. De acordo com Dejours e Abdoucheli (2011), o sofrimento é concebido como a vivência subjetiva intermediária entre a doença e o bem-estar psíquico, que exige o constante "estado de luta" do trabalhador, incluído neste contexto as estratégias defensivas. Por outro lado, a avaliação satisfatória do fator ligado ao reconhecimento no trabalho prediz a existência de um sistema de vivências subjetivas compensatórias em que o prazer se sobrepõe ao sofrimento.

Quanto à análise da variabilidade das respostas dadas pelo desvio padrão, percebe-se que o fator "esgotamento no trabalho" apresenta maior heterogeneidade das respostas. Este resultado reafirma a condição de que as percepções individuais acerca de contextos semelhantes de trabalho variam na medida em que o histórico de vida, os estímulos endógenos e exógenos e as formas de lidar com as vivências de sofrimento também variam (DEJOURS; ABDOUCHELI, 2011).

No que se refere à avaliação da escala de danos relacionados ao trabalho, que aponta as consequências trazidas por fatores físicos e psicossociais inerentes ao contexto do trabalho, é composta pelos seguintes fatores: "danos físicos" relacionados às dores no corpo e distúrbios biológicos; "danos sociais" definidos como isolamento e dificuldades nas relações familiares e sociais; e "danos psicológicos" condizentes aos sentimentos negativos em relação a si mesmo e à vida em geral (MENDES; FERREIRA, 2007).

Os itens propostos pelos fatores desta escala retratam situações muito graves relacionadas à saúde, por isso, a sua aparição e repetição num nível moderado já significa adoecimento. Entretanto, verifica-se, por meio da Figura 5, que os valores das médias para os três fatores não ultrapassou 1,9 , o que denota avaliação mais positiva, retratando uma condição suportável dos danos ali representados. No entanto, o fator "danos físicos" apresentou maior variabilidade de respostas com maior desvio padrão. Este resultado indica o dever de ponderação para as conclusões deste fator, já que pode ser explicado pela diversidade de contextos de trabalho e diversidade entre tipos de deficiência dos participantes deste estudo.

Em síntese, verificam-se, a partir deste estudo, os fatores críticos para o adoecimento no trabalho, condizentes à "organização do trabalho", "custo afetivo", "custo cognitivo" e "esgotamento profissional". Entre estes, o mais preponderante, com relação aos valores de médias apresentados, condiz

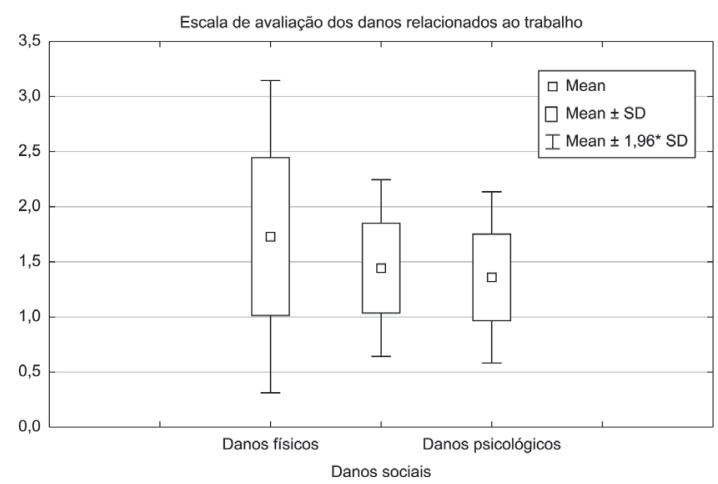

Figura 5. Resultados da EADRT.

com o "custo cognitivo". Os itens que compõem este fator podem ser ajustados pelos gestores públicos, que devem estar atentos à intensidade e volume de demanda impostos aos servidores com deficiência, na medida em que se deve considerar o histórico de vida, a experiência profissional, as habilidades e aptidões, além dos limites e restrições para a execução das atividades inerentes ao posto de trabalho.

Em contrapartida, verificaram-se médias mais elevadas dos fatores que promovem vivências de prazer, destacando-se os fatores ligados à "realização no trabalho" e "liberdade de expressão", com valores de média acima de 4. Além disso, os resultados não apontam para existência de danos relacionados ao trabalho, com valores de média que representam avaliação positiva, em que todos os fatores correspondentes a esta última escala apresentam avaliação suportável.

\section{Considerações finais}

O presente estudo partiu da premissa sobre a inclusão das pessoas com deficiência no trabalho para além do cumprimento da legislação vigente, não restrita apenas à garantia da reserva de vagas em concursos públicos e cotas em empresas privadas. Tem em vista o histórico de discriminação e segregação destas pessoas que abre caminho para vivências que impedem a plena inclusão às tarefas de trabalho, como a subestimação de habilidades e capacidades, e tratamento paternalista. Neste aparato, incluem-se as percepções sobre si mesmas, que podem representar fator agravante, conforme retratam Leão e Silva (2012, p. 167): “[...] a precária percepção do contexto sobre a deficiência e à qual atribuem responsabilidade pelo seu baixo status profissional [...]".

Os estudos que abarcam a teoria da Psicodinâmica do Trabalho, ao contrário de mascarar uma realidade que muitas vezes é omitida, têm por intuito caracterizar as peculiaridades dos processos de subjetivação das relações de trabalho, sobretudo as que provocam 
vivências de prazer e sofrimento que podem ou não culminar em adoecimento.

No presente estudo, os fatores críticos identificados foram: "custos cognitivos" e "custos afetivos"; "organização do trabalho"; e "esgotamento profissional". Os quais estão intimamente ligados, uma vez que a organização do trabalho, típica das atividades desempenhadas em cargos burocráticos, propõe tarefas repetitivas, com intensa fiscalização do desempenho. Além de outras características que exigem do servidor custos cognitivos (como: concentração, memória e desafios intelectuais, entre outros) e custos afetivos, relativos ao controle das emoções decorrentes de cunho emocional/psicológico vivenciado no ambiente de trabalho.

Estes fatores culminam na avaliação crítica para o fator "esgotamento profissional", sendo que os itens mais significativos correspondem ao "estresse" e "sobrecarga do trabalho". Não é possível existir uma organização do trabalho em que não haja sofrimento para os trabalhadores, no entanto é possível identificar organizações do trabalho mais inclinadas à superação do sofrimento do que outras, pois a saúde e o prazer no trabalho perfazem condições que estão sempre a ser conquistadas (MENDES, 2007b).

A avaliação crítica dos fatores denota estado de alerta para o contexto de trabalho destas pessoas, requerendo providências imediatas a curto e médio prazo, para que, no futuro, não sejam catalisadores para o desencadeamento de doenças ocupacionais. Além do que, uma vez diagnosticados os fatores causadores de sofrimento, pode-se, de certa maneira, promover mudanças internas na organização do trabalho, de convivência e melhoria do clima organizacional, além de abrir espaços para as relações entre a equipe de trabalho e chefias, servindo como alternativa de enfrentamento ao esgotamento profissional.

Entretanto os indicadores de vivências de prazer no trabalho apresentaram valores de média elevados, que correspondem aos fatores de realização profissional $(4,17)$ e reconhecimento no trabalho $(4,23)$, sendo que a escala que trata dos danos relacionados ao trabalho apresentou avaliação "suportável", que denota, entre os valores da escala, avaliação mais positiva para a saúde dos participantes. Dessa forma, o estudo caracterizou o serviço público federal de Santa Maria como ambiente de trabalho favorável para as pessoas com deficiência.

Destaca-se, que a produção acadêmica sobre este assunto é extremamente importante, pois as pesquisas empíricas sobre políticas públicas de inclusão das pessoas com deficiência poderão refletir o grau de eficácia e eficiência no alcance de suas finalidades.

\section{Referências}

ANCHIETA, V. C. C. et al. Trabalho e riscos de adoecimento: um estudo entre policiais civis. Psicologia: Teoria e
Pesquisa, v. 27, n. 2, p. 199-208, 2011. http://dx.doi. org/10.1590/S0102-37722011000200007

BONFANTE, P. S. Reserva de vagas em concursos públicos para pessoas com deficiências: do edital à nomeação. Revista Amicus Curiae, v. 4, n. 4, p. 1-22, 2007. Disponível em: <http://periodicos.unesc.net/index.php/ amicus/article/view/221> Acesso: mar. 2012.

BELTRÃO, D. C.; BRUNSTEIN, J. Reconhecimento e construção da competência da pessoa com deficiência na organização em debate. Revista de Administração, v. 47, n. 1, p. 7-21, 2012. http://dx.doi.org/10.5700/ rausp1022

BRASIL. Lei n. 8.112, de 11 dezembro de 1990. Dispõe sobre o regime jurídico dos servidores públicos da União, das autarquias e das fundações públicas federais. Diário Oficial da União, Poder Executivo, Brasília, DF, 12 dez. 1991a. Disponível em: <www010.dataprev. gov.br/sislex/paginas/42/1990/8112.htm>. Acesso em: abr. 2012.

BRASIL. Lei n. 8.213, de 24 de julho de 1991. Dispõe sobre os Planos de Benefícios da Previdência Social e dá outras providências. Diário Oficial da União, Poder Executivo, Brasília, DF, 25 jul. 1991b. Disponível em: <www.planalto.gov.br/ccivil_03/leis/18213cons.htm>. Acesso em: abr. 2012.

BRASIL. Decreto n. 5.296, de 2 de dezembro de 2004. Regulamenta as Leis $\mathrm{n}^{\circ} 10.048$, de 8 de novembro de 2000, que dá prioridade de atendimento às pessoas que especifica, e 10.098, de 19 de dezembro de 2000, que estabelece normas gerais e critérios básicos para a promoção da acessibilidade das pessoas portadoras de deficiência ou com mobilidade reduzida, e dá outras providências. Diário Oficial da União, Poder Executivo, Brasília, DF, 2 dez. 2004. Disponível em <http://www. planalto.gov.br/ccivil_03/_ato2004-2006/2004/decreto/ d5296.htm>. Acesso em: 25 mar 2012.

BRASIL. Ministério do Trabalho e Emprego. Relatório de gestão 2003-2010. Brasília, 2011. 64 p. Disponível em<http://portal.mte.gov.br/data/files/8A7C816A2E731 1D1012FC5A282A06D8E/relatorio_gestao_2003-2010. pdf $>$ Acesso em: maio 2012.

CARVALHO-FREITAS, M. N. Inserção de gestão de trabalho de pessoas com deficiência: um estudo de caso. Revista de Administração Contemporânea, v. 13, p. 121-138, 2009. http://dx.doi.org/10.1590/ S1415-65552009000500009

CARVALHO-FREITAS, M. N. et al. Socialização organizacional de pessoas com deficiência. Revista de Administração de Empresas, v. 50, n. 3, p. 264-275, 2010. http://dx.doi.org/10.1590/ S0034-75902010000300003

DEJOURS, C.; ABDOUCHELI, E. Itinerário teórico em psicopatologia do trabalho. In: BETIOL, M. I. S. (Org.) Psicodinâmica do trabalho: contribuições da escola dejouriana à análise da relação prazer, sofrimento e trabalho. São Paulo: Atlas, 2011. p. 119-143.

GARCIA, V. G. Panorama da inclusão das pessoas com deficiência no mercado de trabalho no Brasil. Trabalho, Educação e Saúde, v. 12, n. 1, p. 165-187, 2014. http:// dx.doi.org/10.1590/S1981-77462014000100010 
GARCIA, A. B. et al. Prazer no Trabalho de técnicos de enfermagem do pronto-socorro de um hospital universitário público. Revista Gaúcha de Enfermagem, v. 33, n. 2, p. 153-159, 2012. PMid:23155594.

GIL, A. C. Métodos e técnicas de pesquisa social. 4. ed. São Paulo: Atlas, 1994.

GOMES, F.; ARAÚJO, R. Pesquisa quanti-qualitativa em administração: uma visão holística do objeto em estudo. In: SEMINÁRIOS EM ADMINISTRAÇÃO, 8., 2005, São Paulo. Anais... São Paulo: FEA-USP, 2005.

INSTITUTO BRASILEIRO DE GEOGRAFIA E ESTATÍSTICA - IBGE. Censo 2010. Disponível em: $<$ http://www.ibge.gov.br/home/estatistica/populacao/ censo2010>. Acesso em jun. 2012.

LANCILLOTTI, S. S. Deficiência e trabalho: redimensionando o singular no contexto universal. Campinas: Autores Associados, 2003. 111 p.

LEÃO, M. A. B. G.; SILVA, L. S. Vivências de trabalhadores com deficiência: uma análise à luz da Psicodinâmica do Trabalho. Revista brasileira Saúde ocupacional, v. 37, n. 125, p. 159-169, 2012.

MENDES, M. M. Da psicodinâmica à psicopatologia do trabalho. In: MENDES, M. M. (Org.). Psicodinâmica do trabalho: teoria, método e pesquisas. São Paulo: All Books Casa do Psicólogo, 2007a. p. 29-48. PMid:17364507.

MENDES, M. M. Novas formas de organização do trabalho, ação dos trabalhadores e patologia sociais. In: MENDES, M. M. (Org.). Psicodinâmica do trabalho: teoria, método e pesquisas. São Paulo: All Books Casa do Psicólogo, 2007b. p. 50-59. PMid:17447639.

MENDES, M. M.; FERREIRA, M. C. Inventário sobre trabalho e riscos de adoecimento - Itra: instrumento auxiliar de diagnóstico de indicadores críticos no trabalho. In: MENDES, M. M. (Org.). Psicodinâmica do trabalho: teoria, método e pesquisas. São Paulo: All Books Casa do Psicólogo, 2007. p. 111-125.
MONTAGNER, P. et al. Diversidade e capacitação em escolas de governo: mesa-redonda de pesquisa-ação. Brasília: ENAP, 2010. 112 p.

PEREIRA, A. C. C.; PASSERINO, L. Um estudo sobre o perfil dos empregados com deficiência em uma organização. Revista Brasileira de Educação Especial, v. 18, n. 2, p. 245-264, 2012. http://dx.doi.org/10.1590/ S1413-65382012000200006

SANTOS JÚNIOR, A. V.; MENDES, A. M.; ARAUJO, L. K. R. Experiência em clínica do trabalho com bancários adoecidos por Ler/ Dort. Psicologia Ciência e Profissão, v. 29, n. 3, p. 614-625, 2009. http://dx.doi.org/10.1590/ S1414-98932009000300014

SILVEIRA, L. C.; GUILAM, M. C. R.; OLIVEIRA, S. R. Psicodinâmica do Trabalho na medicina nuclear com o Iodo-131. Ciência \& Saúde Coletiva, v. 18, n. 11, p. 3169-3174, 2013. PMid:24196882. http://dx.doi. org/10.1590/S1413-81232013001100007

SIMONELli, A. P.; CAMAROTTO, J. A. Análise de atividades para a inclusão de pessoas com deficiência no trabalho: uma proposta de modelo. Gestão \& Produção, v. 18, n. 1, p. 13-26, 2011. http://dx.doi.org/10.1590/ S0104-530X2011000100002

SCOLARI, C.; COSTA, S. G.; MAZZILLI, C. Prazer e sofrimento entre os trabalhadores de call center. Psicologia USP, v. 20, n. 4, p. 555-576, 2009. http:// dx.doi.org/10.1590/S0103-65642009000400005

VASCONCELOS, F. D. O trabalhador com deficiência e as práticas de inclusão no mercado de trabalho de Salvador, Bahia. Revista Brasileira de Saúde Ocupacional, v. 35, n. 121, p. 41-52, 2010. http://dx.doi.org/10.1590/ S0303-76572010000100006

VILELA, E. F.; GARCIA, F. C.; VIEIRA, A. Vivências de prazer-sofrimento no trabalho do professor universitário: estudo de caso em uma instituição. Revista Eletrônica de Administração, v. 19, n. 2, p. 517-540, 2013. http:// dx.doi.org/10.1590/S1413-23112013000200010 